(c) American Dairy Science Association, 2006.

\title{
Characterization of Bacterial Susceptibility Isolates in Sixteen Dairy Farms in Taiwan
}

\author{
Y. P. Ma, ${ }^{\star}$ S. K. Chang, ${ }^{*}$ and C. C. Chou $^{*} \dagger^{1}$ \\ *Department of Veterinary Medicine, and \\ †Center for Zoonoses Research, College of Bio-Resources and Agriculture, National Taiwan University, No. 1, Sec. 4, \\ Roosevelt Rd., Taipei 106, Taiwan
}

\section{ABSTRACT}

Bacteria were isolated from dairy cows, dairy farm environments, and dairy workers in 2 geographically different areas of eastern and northern Taiwan. Isolates were evaluated for antimicrobial susceptibility and the phylogenetics of isolated Escherichia coli O157:H7 were characterized. A total of 1,346 bacteria were identified, including $226 \mathrm{E}$. coli, 30 Pseudomonas spp. (7 Pseudomonas aeruginosa), 259 other gram-negative bacteria, 271 Enterococcus spp., 314 Staphylococcus spp., 195 Streptococcus spp., and 51 other grampositive bacteria. Among them, $88 \%(1,184 / 1,346)$ of the isolates were resistant to sulfadimethoxine. The percentages of gram-negative bacteria resistant to oxytetracycline and streptomycin were 48\% (249/515) and $78 \%$ (404/515), respectively. Gram-positive bacteria isolated from eastern Taiwan, the least polluted region of Taiwan, were found to have greater antimicrobial resistance than those isolated from northern Taiwan. Two $E$. coli $\mathrm{O} 157: \mathrm{H} 7$ from 2 different geographical areas were isolated. Both were $v t 2$-positive but $v t 1$-negative and had phylogenetic similarities of 82 and $67 \%$, respectively, compared with previous isolates. Information on antimicrobial susceptibility revealed from this dairy farm survey may serve as a baseline for future studies and may also highlight the need to formulate better regulation strategies for the safe use of antimicrobials on food-producing farms.

Key words: antimicrobial resistance, dairy farm, Escherichia coli $\mathrm{O} 157: \mathrm{H} 7$

\section{INTRODUCTION}

There are growing concerns regarding the increased prevalence of antimicrobial resistance worldwide (WHO, 2001). It is now generally accepted that the main risk factor for increased resistance in pathogenic bacteria is the increasing use of antimicrobials (Cru-

Received March 9, 2005.

Accepted June 21, 2006.

${ }^{1}$ Corresponding author: chouchin@ntu.edu.tw chaga et al., 2001). Inappropriately applied antimicrobials may promote resistance selection and can increase the gene pool of pathogens with antimicrobial resistance. Antimicrobial resistance could in turn facilitate the growth of these bacteria in certain risk areas, such as hospitals, and result in difficult treatment (Lee, 2003).

The use of large amounts of antimicrobial drugs for disease control in food-animal production is suspected to play a role in the spread and persistence of antimicrobial-resistant zoonotic bacteria (Witte, 1998). Selection pressure imposed by the use of antimicrobial drugs in animal production could be a driving force in the selection for antimicrobial resistance in microbes (Schroeder et al., 2002). It has been suggested that use of avoparcin is associated with the occurrence of vancomycin-resistant enterococci (VRE) in domestic animals (Bager et al., 1997), and that strains of methicillin (oxacillin)resistant Staphylococcus aureus isolated from major food animals are a possible source of human infections (Lee, 2003). More information is needed to assess the global risk of the emergence and spread of resistant isolates in different farm environments (Bager et al., 1997; Martel et al., 2000).

High percentages of antimicrobial resistance among many common pathogenic bacteria in humans have been reported in Taiwan. The VRE were found in 22 major regional hospitals in all regions of Taiwan (Ho et al., 1999). The isolation rate of VRE was $14 \%$, and that was determined to be $70 \%$ of Enterococcus faecalis, $15 \%$ of Enterococcus faecium, and 15\% of other Enterococcus spp. About $8 \%$ of the Enterobacter spp. were resistant to ciprofloxacin, and 50\% of Staph. aureus causing nosocomial infections were methicillin-resistant Staph. aureus. Chang et al. (2003) estimated that about 70 to $76 \%$ of the total quantity (mass in kilograms) of antimicrobials consumed annually in Taiwan were used for animals. Bacteria isolated from broilers, poultry farms, and chick-raising farmers in Taiwan had great similarities in their antimicrobial resistance patterns. Susceptibilities to clindamycin, erythromycin, penicillin $\mathrm{G}$, and tetracycline were small in isolated bacteria, which can cause difficulty in medical treat- 
ment (Chou et al., 2003). Gram-negative bacteria isolated from pigs and their surrounding environments in Taiwan expressed large percentages of antimicrobial resistance, and multiresistant antimicrobial strains also were noted.

The antimicrobials used on dairy farms are mostly for the treatment of mastitis (Kaneene and Miller, 1992). Monitoring the patterns of antimicrobial resistance to mastitis-causing pathogens is important in facilitating the selection of antimicrobials for treatment of affected cows (Craven et al., 1986). Staphylococcus spp., Streptococcus spp., Pseudomonas spp., gram-negative bacteria, and hygienic indicator bacteria (E. coli and Enterococcus spp.) have been reported to be associated with mastitis in cows, and all have shown resistance to antimicrobials (Martel et al., 2000; Wallmann et al., 2003). Few antimicrobial sensitivity reports have been documented for dairy cows in Taiwan. Thus, this study investigated the above-mentioned bacterial susceptibility to antimicrobials in 3 sampling venues: dairy cows, dairy workers, and dairy farm environments. Our interest was not only to provide resistance references for clinical consultation, but also to seek out differences in resistance patterns and their possible correlations. The association between bacterial resistance and different infection status and pollution levels was tested at 2 different geographical areas distinguished by their natural geographical environment and pollution status. The rationale was that in a less-polluted area in which relatively fewer antimicrobials are used, less resistance to antimicrobials may develop. Because cattle are the primary reservoirs of zoonotic pathogens such as $E$. coli O157:H7, an important foodborne human pathogen, this study also investigated the prevalence of $E$. coli O157:H7 in milking environments and monitored genetic variation in the isolated bacteria.

\section{MATERIALS AND METHODS}

\section{Sampling}

Cross-sectional studies were designed to investigate the resistance of bacteria from dairy farm-associated environments, cows, and workers, and also the point prevalence of $E$. coli $\mathrm{O} 157: \mathrm{H} 7$ at both the herd and the individual cow level. Dairy farms in Taiwan enroll in their respective county or city Animal Disease Control Center. At the time of sampling, registered dairy farms in northern Taiwan were from Taipei $\operatorname{City}(\mathrm{n}=1)$, Taipei County ( $\mathrm{n}=9$ ), Taoyuan County $(\mathrm{n}=44)$, and Hsinchu County $(\mathrm{n}=17)$. Registered dairy farms in eastern Taiwan were in Hualien County $(\mathrm{n}=10)$ and Taitung County $(n=9)$. Sixteen attendant dairy farms were selected from different sampling districts according to the owners' willingness to cooperate. Among these were
11 farms in northern Taiwan, specifically, in Taipei City $(n=1)$, Taipei County $(n=3)$, Taoyuan County $(\mathrm{n}=4)$, and Hsinchu County $(\mathrm{n}=3)$; and 5 farms in eastern Taiwan, specifically, in Hualien County $(\mathrm{n}=3)$ and Taitung County $(n=2)$. Herd sizes of these dairy farms were between 110 and 250 Holstein cows. Onsite questionnaires were administered before sampling to elicit basic information about each farm, the number of cows, vaccination programs, the kinds of antimicrobials used, treatment and disease records of the dairy cows, and basic information about the workers (e.g., age, gender, working experience, and physical conditions). Human consent forms were filed before collecting samples from the dairy workers.

Based on our previous study of bacterial resistance to commonly used antimicrobials on Taiwanese farms, the prevalence of bacterial resistance in animals (broilers and pigs) and in their environments was generally greater than 50\% (Chou et al., 2003). A farm with a prevalence of $50 \%$ antimicrobial resistance to bacteria requires sampling of at least 5 cows from each farm (Cannon and Roe, 1982). In this bacterial susceptibility study, the authors sampled 6 adult dairy cows, 4 different environments (influent and effluent water, floor surfaces, and feed) and as many dairy workers as possible from each farm. Depending on the dairy workers' operational preferences and on the facilities for restraining the dairy cows, samples were collected before or shortly after milking. Samples collected for dairy cows were raw and bulk-tank milk samples, udder surface samples, and fecal rectal samples. Of the milk samples, 6 samples of individual raw milks and 1 sample of bulktank milk $(\sim 150 \mathrm{~mL})$ were collected from each dairy farm during the morning milking. An aseptic cottontipped swab was dipped into the milk and then streaked for isolation directly onto different selective media. Target microbes were E. coli, Pseudomonas spp. (Pseudomonas aeruginosa), Enterococcus spp., Staphylococcus spp., and Streptococcus spp.). A PBS-rinsed aseptic cotton swab was smeared over the udder surface after towel-cleaning the teat end before milking. Udder surface samples were collected to detect possible residual or contaminating bacteria. For the fecal samples, the anuses of the sampled cattle were swabbed with a PBSrinsed aseptic cotton swab. Each different sampling swab was then plated directly onto different selective media.

The environmental samples collected were from influent and effluent water, floor surfaces, and feed. Both types of water samples were collected in $1,000-\mathrm{mL}$ aseptic bottles and shipped in a $4^{\circ} \mathrm{C}$ dark environment to the laboratory. Samples were then filtered $(0.45 \mu \mathrm{m})$. Filtration papers were placed into PBS and cultured with different selective media. Floor surface samples 
were collected by smearing the PBS-rinsed aseptic cotton swabs over $6 \times \sim 25 \mathrm{~cm}^{2}$ areas, which were then plated onto different selective media. Feed from each farm was collected randomly in sterile tubes and shipped to the laboratory, where they were ground, soaked, and filtered with PBS. Filtrates were then cultured in selective media.

It was almost impossible to collect a fresh stool or rectal swab sample from dairy workers. Samples were thus collected from dairy workers by smearing PBSrinsed aseptic cotton swabs over nostrils and oral cavities and then streaking them directly onto the selective media for isolation and identification. Human samples may compromise the enteric bacterial flora, but have the advantage of including ongoing exposure to the housing environments of cows, as well as that in their own living quarters.

\section{Isolation and Identification of Bacteria}

Each sample was cultured onto a designated selected medium for the target bacteria as follows: Baird-Parker agar (Difco, Sparks, MD) for Staphylococcus spp., cetrimide agar (Difco) for Pseudomonas spp., MacConkey agar (Difco) for $E$. coli, modified trypticase soy broth (mTSB; Merck, Darmstadt, Germany) for E. coli O157:H7, streptococcus selective agar (Merck) for Streptococcus spp., and enterococcosel broth (BBL, Cockeysville, MD) for Enterococcus spp. Isolates from the appropriate agar were subcultured onto plates 3 times to check for purity and further identification. Gram reaction, morphology, and biochemical tests were performed for presumptive identification purposes. Enterococcus spp. and Streptococcus spp. were confirmed by rapid ID 32 strep (bioMérieux sa, La Balme les Grottes, France) biochemical tests. Gram-negative bacteria were identified using a GFB-14E system (Jeou Chou Co., Taipei, Taiwan). Pseudomonas spp. were identified using an ID 32 GN identification kit (bioMérieux sa).

\section{Antimicrobial Substances}

Antimicrobials to be tested were selected according to 3 criteria: substances commonly used on dairy farms, substances having different mechanisms of action for veterinary medical applications, and substances used for human medical purposes (resistant strains having a potential public health impact). The antimicrobials used for susceptibility testing in gram-negative microbes were amikacin from Shin-Don (Taoyuan, Taiwan), amoxicillin from Union (Taipei, Taiwan), ceftiofur from Pharmacia \& Upjohn (Kalamazoo, MI), cephazolin, chloramphenicol, colistin, doxycycline, oxytetracycline, streptomycin, and sulfadimethoxine from
Sigma (St. Louis, MO), and enrofloxacin from Fluka (Buchs, Switzerland). Chemicals used for gram-positive bacterial susceptibility testing were amoxicillin/clavulanic acid from Beechem (Brentford, UK), cephalothin, chloramphenicol, doxycycline, oxacillin, oxytetracycline, penicillin G, and sulfadimethoxine from Sigma, enrofloxacin from Fluka, erythromycin, and vancomycin from Abbott Labs (Chicago, IL).

\section{Antimicrobial Susceptibility Testing (Agar Dilution Method)}

All identified bacteria were tested for 11 different gram-positive or negative antimicrobial agents by using Mueller-Hinton agar (Difco), whereas 5\% sheep blood was added when testing Streptococcus spp. To explore susceptibility differences among a subset of Enterococcus spp., Staph. aureus, Streptococcus spp., and E. coli, MIC were determined using the agar dilution method in accordance with the standards described in the $\mathrm{Na}$ tional Committee for Clinical Laboratory Standards (NCCLS, 1999), including suggested breakpoints to determine susceptibility and resistance. Results were scored as susceptible $(\mathbf{S})$, intermediate $(\mathbf{I})$, and resistant (R), whereas results ranging between S and R, but only $\mathrm{S}$ and $\mathrm{R}$ categories recommended by the National Committee for Clinical Laboratory Standards, were scored as I. Staphylococcus aureus American Type Culture Collection (ATCC) 29213, E. faecalis ATCC 29212, E. coli ATCC 25922, and E. coli 35218 were included as quality controls with each batch of organisms tested.

\section{Serotyping and Genotyping of E. coli 0157:H7 Isolates}

Isolates enriched in mTSB were spread on CT-sMAC plates (Merck) and the suspected pale-gray to colorless and nonfermenting sorbitol colonies were mixed with O157 antiserum (Seiken, Denka Seiken Co., Tokyo, Japan) on a glass slide. Granular agglutination patterns occurred within 1 min. A reference E. coli O157:H7 and normal saline were used as positive and negative controls, respectively. Polymerase chain reaction was used to analyze the genotypes of the isolates and the reference $E$. coli $\mathrm{O} 157: \mathrm{H} 7$ strains by detection of DNA fragments of the $\mathrm{O} 157$ antigen $r f b$ gene, the $\mathrm{H} 7$ antigen fic C gene, and the verocytotoxin (VT)-producing genes $v t 1$ and $v t 2$ according to previously published primers (Pan et al., 2002). Test strains were grown overnight in trypticase soy broth (Difco) at $37^{\circ} \mathrm{C}$. The DNA template for PCR was prepared by boiling the culture in water for $10 \mathrm{~min}$. The PCR assays were performed in $25 \mu \mathrm{L}, 0.2 \mu M$ (each) primer set, 10× PCR buffer, 0.2 $\mathrm{mM}$ (each) deoxynucleotide triphosphate, 1.5 U of Taq 
DNA polymerase (MDBio, Inc., Taipei, Taiwan). Five different VT-producing $E$. coli O157:H7 strains (ATCC 35150, ATCC 43889, ATCC 43890, ATCC 43894, and ATCC 43895) were selected as references. Reaction mixtures were processed through 35 cycles in a PCR express thermal cycler (Perkin Elmer Co., Forest, CA). Samples were heated to $94^{\circ} \mathrm{C}$ for $5 \mathrm{~min}$, followed by 35 cycles of denaturation at $94^{\circ} \mathrm{C}$ for $30 \mathrm{~s}$, annealing at $55^{\circ} \mathrm{C}$ for 30 $\mathrm{s}$, extension at $72^{\circ} \mathrm{C}$ for $30 \mathrm{~s}$, final extension at $72^{\circ} \mathrm{C}$ for $10 \mathrm{~min}$, and then cooling to $4^{\circ} \mathrm{C}$. The amplified product was visualized by ethidium bromide staining after gel electrophoresis of $5 \mu \mathrm{L}$ of the final reaction mixture on $1.5 \%$ agarose. The identified isolates were further analyzed by using pulsed-field gel electrophoresis after $X b a \mathrm{I}$ digestion to compare the similarity with previous E. coli O157:H7 isolates in Taiwan.

\section{Statistical Analyses}

Each isolate was assigned the required information, including identity of the farm and cow, general information on the workers, antimicrobials regularly used on the farm, source of the individual isolate, genus (or species) of the isolates, and results of the antimicrobial susceptibility tests. A $\chi^{2}$ test was used to distinguish the difference in resistance between different sample sources. The $\mathrm{R}$ strain was treated as a positive result; the I and $\mathrm{S}$ strains were treated as a negative result. An ANOVA procedure (SAS Inst. Inc., Cary, NC) was used to determine the bacterial resistance between different antimicrobials and farms (sources). Input data were transformed from the original bacterial antimicrobial susceptibility results $(R+I+S)$ into percentages of resistance $(R)$ and nonresistance $(\mathrm{I}+\mathrm{S})$ of each bacteria genus under each antimicrobial category. Duncan's multiple range tests were applied to further identify source differences. Associations were considered to be significant when $P<0.05$. To define the correlation between bacteria isolated from dairy workers and bacteria isolated from bovines and from farm environments, regressions were approached by using the percentage of resistance of each bacteria genus to different antimicrobials. Correlation coefficients were calculated.

\section{RESULTS}

The on-site investigations revealed that there were generally 2 full-time workers and another 1 to 2 parttime workers on each dairy farm. A total of 30 dairy workers attended these investigations. The average age of the worker was $40.9 \mathrm{yr}$ (range of 20 to $60 \mathrm{yr}$ ), with an average working experience of $13.2 \mathrm{yr}$ (range of 1 to $42 \mathrm{yr}$ ), and the average daily working hours were 9.1 (range of 5 to 18).
A total of 1,346 strains of bacteria were isolated from 3 different sample sources (Table 1). The numbers of isolated bacteria, in decreasing order, were Staphylococcus $\mathrm{spp}$. ( $\mathrm{n}=314)$, Enterococcus $\mathrm{spp}$. $(\mathrm{n}=271)$; other gram negatives ( $\mathrm{n}=259)$, E. coli $(\mathrm{n}=226)$, Streptococcus spp. $(\mathrm{n}=195)$; other gram positives $(\mathrm{n}=51)$; and Pseudomonas spp. $(\mathrm{n}=30)$. Seven $P$. aeruginosa were identified. Bacteria from udder surfaces and bovine feces (58\%) dominated the isolates. Fecal bacteria-E. coli, Streptococcus spp., and Enterococcus spp.-comprised $50 \%$ of all the isolates. Fifty-five percent (80/145) of isolates from workers were Staphylococcus spp. Figure 1 shows that bacteria from dairy workers had an antimicrobial resistance pattern very close to those isolated from bovine and environmental sources $\left(R^{2}=0.80\right)$. Bacteria from bovines and the environment had the largest correlation with antimicrobial resistance $\left(\mathrm{R}^{2}=\right.$ $0.92)$. In contrast, the correlation for bacterial antimicrobial resistance between environments and dairy workers was 0.75 , and between cows and dairy workers was 0.78 .

Table 2 shows the antimicrobial susceptibility results of 515 gram-negative isolates. Amikacin, ceftiofur, and enrofloxacin were the 3 most effective antimicrobials against gram-negative isolates. We noted extremely low sensitivity $(<10 \%)$ to chloramphenicol and sulfadimethoxine of isolates of all 3 origins, and $<50 \%$ of the gramnegative isolates were sensitive to amoxicillin, doxycycline, oxytetracycline, and streptomycin (apart from $52.6 \%$ of the human isolates sensitive to streptomycin). Gram-negative bacteria isolated from bovine and environmental samples at farms in Taipei County had greater $(P<0.001)$ resistance to streptomycin than those from human sources. In contrast, bacteria isolated from human sources in Taipei County had greater $(P<0.05)$ resistance to amoxicillin than those from bovine and environmental samples. There was a high correlation $\left(R^{2}=0.78\right)$ between gram-negative bacteria of worker origin that were resistant to antimicrobials and those of bovine and environmental origin.

The antimicrobial susceptibilities of the gram-negative bacilli $E$. coli and $P$. aeruginosa are given in Table 3 . The $E$. coli showed extremely high sensitivity $(>90 \%)$ to amikacin, ceftiofur, and enrofloxacin, and $P$. aeruginosa had high sensitivity to amikacin and colistin. Of both sources of samples, $E$. coli were found to be more ( $P$ $<0.05$ ) susceptible to amoxicillin, ceftiofur, cephazoline, doxycycline, enrofloxacin, and oxytetracycline than was $P$. aeruginosa. Thirty-nine strains (17.3\%) of multiresistant $E$. coli (resistant to $>5$ antimicrobial drugs) also were detected in this study.

Amoxicillin/clavulanic acid, chloramphenicol, doxycycline, penicillin $\mathrm{G}$, and vancomycin were relatively effective antimicrobial drugs against Enterococcus spp., 
Table 1. Numbers of bacterial isolates of different origins from 16 Taiwanese dairy farms

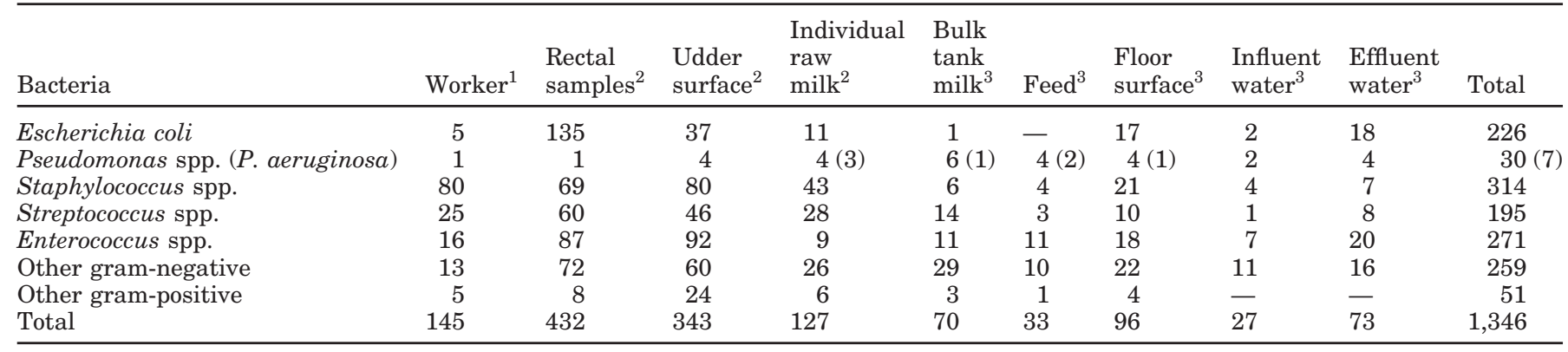

${ }^{1}$ Sample numbers $=30$.

${ }^{2}$ Sample numbers $=96$.

${ }^{3}$ Sample numbers $=16$.

Staphylococcus spp., and Streptococcus spp. (Table 4). Enterococcus spp. isolated from human sources had greater $(P<0.05)$ resistance to erythromycin than those isolates from bovine and environmental sources. Grampositive isolates from dairy workers had antimicrobial resistant patterns similar to the isolates from bovine and environmental sources $\left(R^{2}=0.82\right)$. One vancomycin-resistant $E$. faecium $(\mathrm{MIC}=512 \mu \mathrm{g} / \mathrm{mL}$ ) from bovine rectal samples and one vancomycin-resistant $E$. faecalis (MIC $=128 \mu \mathrm{g} / \mathrm{mL}$ ) from bovine udder surface samples were detected. For all 3 sources of Staphylococcus spp., amoxicillin/clavulanic acid, cephalothin, chlorampheni- col, doxycycline, enrofloxacin, and vancomycin showed less than $20 \%$ resistance. Staphylococcus spp. from human and environmental sources had greater $(P<0.001)$ resistance to oxytetracycline and sulfadimethoxine than those from bovine sources. However, Staphylococcus spp. from human sources had penicillin $\mathrm{G}$ resistance greater $(P<0.001)$ than those from bovine and environmental sources. In this study, 18 oxacillin-resistant coagulase-positive Staphylococcus spp. (ORS) were isolated from human sources $(n=7)$, feed and floor surfaces ( $\mathrm{n}=4)$, and bovine sources $(\mathrm{n}=7)$. Enterococcus spp. and Streptococcus spp. all had $>90 \%$ resistance to sul-

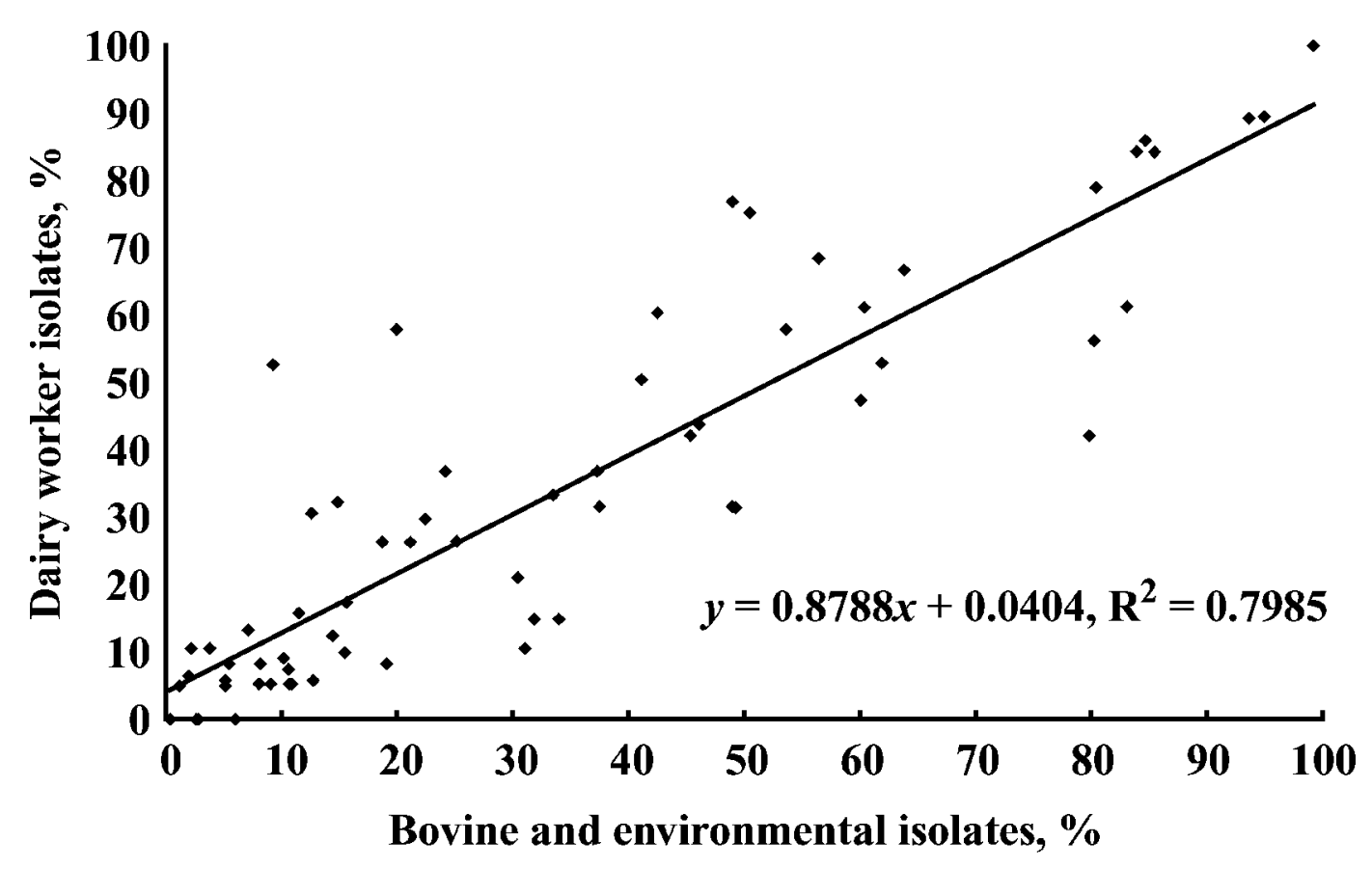

Figure 1. Antimicrobial resistance correlation between bacterial isolates from dairy workers and bacterial isolates from bovine and environmental sources on 16 Taiwanese dairy farms. These data are grouped into bacterial susceptibility (percentages of resistance) of the same bacteria genus to 11 gram-positive or 11 gram-negative antimicrobial agents. 
Table 2. Antimicrobial susceptibility ${ }^{1}$ of 515 gram-negative strains isolated from 3 different sources on 16 Taiwanese dairy farms

\begin{tabular}{|c|c|c|c|c|c|c|c|c|c|}
\hline \multirow[b]{2}{*}{ Antimicrobial } & \multicolumn{3}{|c|}{$\begin{array}{l}\text { Bovine, } \% \\
(\mathrm{n}=386)\end{array}$} & \multicolumn{3}{|c|}{$\begin{array}{c}\text { Environment, \% } \\
\quad(\mathrm{n}=110)\end{array}$} & \multicolumn{3}{|c|}{$\begin{array}{l}\text { Human, \% } \\
(\mathrm{n}=19)\end{array}$} \\
\hline & $\mathrm{R}$ & I & $\mathrm{S}$ & $\mathrm{R}$ & I & $\mathrm{S}$ & $\mathrm{R}$ & I & $\mathrm{S}$ \\
\hline Amikacin & 0.3 & 0.3 & 99.5 & 0.9 & 0.9 & 98.2 & 0.0 & 0.0 & 100.0 \\
\hline Amoxicillin & 52.6 & 6.7 & 40.7 & 70.0 & 3.6 & 26.4 & 68.4 & 0.0 & 31.6 \\
\hline Ceftiofur & 11.9 & 6.5 & 81.6 & 10.0 & 13.6 & 76.4 & 15.8 & 5.3 & 78.9 \\
\hline Cephazoline & 33.9 & 10.1 & 56.0 & 49.1 & 5.5 & 45.5 & 36.8 & 11.1 & 57.9 \\
\hline Chloramphenicol & 33.3 & 65.4 & 1.3 & 34.3 & 57.1 & 8.6 & 33.3 & 66.7 & 0.0 \\
\hline Colistin & 19.7 & 18.4 & 61.9 & 26.4 & 20.0 & 53.6 & 26.3 & 26.3 & 47.4 \\
\hline Doxycycline & 31.1 & 22.3 & 46.6 & 28.2 & 30.9 & 40.9 & 21.1 & 36.8 & 42.1 \\
\hline Enrofloxacin & 3.9 & 8.8 & 87.3 & 3.6 & 17.3 & 79.1 & 10.5 & 5.3 & 84.2 \\
\hline Oxytetracycline & 49.0 & 19.2 & 31.9 & 49.1 & 22.7 & 28.2 & 31.6 & 57.9 & 10.5 \\
\hline Streptomycin & 82.4 & 9.1 & 8.5 & 70.9 & 17.3 & 11.8 & 42.1 & 5.3 & 52.6 \\
\hline Sulfadimethoxine & 95.9 & 2.3 & 1.8 & 91.8 & 1.8 & 6.4 & 89.5 & 10.5 & 0.0 \\
\hline
\end{tabular}

${ }^{1} \mathrm{R}=$ Resistant; $\mathrm{I}=$ intermediate; $\mathrm{S}$ = susceptible.

fadimethoxine. For Staphylococcus spp., human isolates had greater resistance than bovine and environmental source isolates toward oxytetracycline $(P<0.05)$ and penicillin $\mathrm{G}(P<0.001)$ in Taipei County, penicillin $\mathrm{G}$ in Hualien County $(P<0.05)$, and doxycycline in Taitung County. In contrast, isolates from bovine and environmental sources had greater $(P<0.05)$ resistance than isolates from humans toward erythromycin in Taipei County.

Of the 16 herds, only $2 E$. coli $\mathrm{O} 157: \mathrm{H} 7$ were isolated. One was from Taipei County (bovine feces) and the other one was from Hualien County (environmental sample). Both were $v t 2$-positive but $v t 1$-negative. The positive isolation rate of $E$. coli $\mathrm{O} 157: \mathrm{H} 7$ from fecal samples of dairy cattle was $1.04 \%$ (1/96), and 1.56\% (1/ 64) for environmental samples. These 2 E. coli $\mathrm{O} 157: \mathrm{H} 7$ isolates were further compared with our previous Tai- wan isolates by pulse-field gel electrophoresis after $\mathrm{XbaI}$ digestion (Figure 2). The strain isolated from eastern Taiwan was closely related to the previous strains, with a similarity of $82 \%$ and only 1 band difference. This strain was resistant to amoxicillin, streptomycin, and sulfadimethoxine. In contrast, the one isolated from northern Taiwan had 7 band differences and only $67 \%$ similarity to the previous ones. This strain was resistant to amoxicillin, chloramphenicol, colistin, doxycycline, oxytetracycline, streptomycin, and sulfadimethoxine.

\section{DISCUSSION}

Antimicrobial resistance is a complex problem worldwide. Many countries are devoted to minimizing public health risks by safeguarding the efficiency of antimicro-

Table 3. Antimicrobial susceptibility ${ }^{1}$ of Escherichia coli and Pseudonomonas aeruginosa strains isolated from 3 different sources on 16 Taiwanese dairy farms

\begin{tabular}{|c|c|c|c|c|c|c|c|c|c|c|c|c|c|c|c|}
\hline \multirow{2}{*}{ Antimicrobial } & \multicolumn{9}{|c|}{ E. coli } & \multicolumn{6}{|c|}{ P. aeruginosa } \\
\hline & \multicolumn{3}{|c|}{$\begin{array}{l}\text { Bovine, } \% \\
\left(\mathrm{n}^{2}=184\right)\end{array}$} & \multicolumn{3}{|c|}{$\begin{array}{c}\text { Environment, } \% \\
(\mathrm{n}=37)\end{array}$} & \multicolumn{3}{|c|}{$\underset{(\mathrm{n}=5)}{\operatorname{Human}, \%}$} & \multicolumn{3}{|c|}{$\begin{array}{l}\text { Bovine, } \% \\
\quad(\mathrm{n}=4)\end{array}$} & \multicolumn{3}{|c|}{$\begin{array}{l}\text { Environment, } \% \\
(\mathrm{n}=3)\end{array}$} \\
\hline Amikacin & 0.0 & 0.5 & 99.5 & 0.0 & 2.7 & 97.3 & 0.0 & 0.0 & 100.0 & 0.0 & 0.0 & 100.0 & 0.0 & 0.0 & 100.0 \\
\hline Amoxicillin & 31.5 & 8.7 & 59.8 & 40.5 & 5.4 & 54.1 & 20.0 & 0.0 & 80.0 & 100.0 & 0.0 & 0.0 & 100.0 & 0.0 & 0.0 \\
\hline Ceftiofur & 3.3 & 2.7 & 94.0 & 8.1 & 0.0 & 91.9 & 0.0 & 0.0 & 100.0 & 100.0 & 0.0 & 0.0 & 66.7 & 0.0 & 33.3 \\
\hline Colistin & 13.0 & 20.7 & 66.3 & 13.5 & 21.6 & 64.9 & 0.0 & 20.0 & 80.0 & 0.0 & 0.0 & 100.0 & 33.3 & 0.0 & 66.7 \\
\hline Doxycycline & 28.8 & 12.0 & 59.2 & 24.3 & 45.9 & 29.7 & 20.0 & 20.0 & 60.0 & 100.0 & 0.0 & 0.0 & 66.7 & 33.3 & 0.0 \\
\hline Enrofloxacin & 2.7 & 2.7 & 94.6 & 2.7 & 8.1 & 89.2 & 0.0 & 0.0 & 100.0 & 25.0 & 75.0 & 0.0 & 33.3 & 66.7 & 0.0 \\
\hline Oxytetracycline & 43.5 & 18.5 & 38.0 & 51.4 & 21.6 & 27.0 & 40.0 & 40.0 & 20.0 & 100.0 & 0.0 & 0.0 & 66.7 & 33.3 & 0.0 \\
\hline Streptomycin & 89.1 & 7.1 & 3.8 & 86.3 & 13.5 & 0.0 & 80.0 & 0.0 & 20.0 & 75.0 & 0.0 & 25.0 & 100.0 & 0.0 & 0.0 \\
\hline Sulfadimethoxine & 97.8 & 1.1 & 1.1 & 94.6 & 5.4 & 0.0 & 100.0 & 0.0 & 0.0 & 100.0 & 0.0 & 0.0 & 100.0 & 0.0 & 0.0 \\
\hline
\end{tabular}

${ }^{1} \mathrm{R}=$ Resistant; $\mathrm{I}$ = intermediate; $\mathrm{S}$ = susceptible.

${ }^{2}$ Strain number.

${ }^{3}$ Human sample size was 3 in the chloramphenicol susceptibility test. 
Table 4. Susceptibility in percentages of Enterococcus spp., Staphylococcus spp., and Streptococcus spp. isolates from 3 different sources ${ }^{1}$ on 16 Taiwanese dairy farms

\begin{tabular}{|c|c|c|c|c|c|c|c|c|c|}
\hline \multirow{2}{*}{ Antimicrobial } & \multicolumn{9}{|c|}{ Percentage of resistant isolates } \\
\hline & \multicolumn{3}{|c|}{$\begin{array}{l}\text { Enterococcus spp. } \\
\quad(\mathrm{n}=271)\end{array}$} & \multicolumn{3}{|c|}{$\begin{array}{l}\text { Staphylococcus spp. } \\
(\mathrm{n}=314)\end{array}$} & \multicolumn{3}{|c|}{$\begin{array}{l}\text { Streptococcus spp. } \\
\quad(\mathrm{n}=195)\end{array}$} \\
\hline Amoxicillin/clavulanic acid & 2.5 & 0.0 & 6.3 & 9.6 & 13.9 & 6.3 & 3.4 & 0.0 & 4.0 \\
\hline Cephalothin & 52.9 & 52.0 & 50.0 & 0.8 & 0.0 & 0.0 & 36.5 & 46.7 & 72.7 \\
\hline Enrofloxacin & 25.1 & 26.8 & 18.8 & 5.6 & 8.3 & 2.5 & 27.0 & 31.8 & 20.0 \\
\hline Erythromycin & 21.6 & 16.1 & 37.5 & 27.8 & 33.3 & 26.3 & 14.9 & 31.8 & 36.0 \\
\hline Oxacillin & 87.9 & 92.9 & 93.8 & 10.6 & 22.2 & 11.3 & 38.5 & 54.5 & 56.0 \\
\hline Oxytetracycline & 50.3 & 51.8 & 62.5 & 30.8 & 55.6 & 51.3 & 37.2 & 27.3 & 40.0 \\
\hline Penicillin G & 11.1 & 12.5 & 12.5 & 16.7 & 11.1 & 40.0 & 11.5 & 0.0 & 12.0 \\
\hline Sulfadimethoxine & 98.0 & 100.0 & 93.8 & 55.1 & 75.0 & 80.0 & 98.0 & 95.5 & 92.0 \\
\hline Vancomycin & 2.5 & 0.0 & 6.3 & 7.1 & 19.4 & 3.8 & 4.7 & 4.5 & 8.0 \\
\hline
\end{tabular}

${ }^{1} \mathrm{~B}$ = Bovine; $\mathrm{E}$ = environment; $\mathrm{H}$ = human.

bial therapy and applying systematic monitoring of zoonotic bacteria of animal origin (Martel et al., 2000; Wallmann et al., 2003). The antimicrobial susceptibilities of most bacteria in this study are quite similar to studies reported from other countries (Erskine et al., 2002; Wallmann et al., 2003). However, differences can be found in Enterococcus spp. in that $11.4 \%$ of our isolates were resistant to penicillin $\mathrm{G}$, in comparison with $0 \%$ of isolates from Finland and $2.5 \%$ of isolates from the United States. Further, $51.1 \%$ of our isolates were resistant to oxytetracycline; in contrast, $73 \%$ of the isolates from Finland and $22.5 \%$ of the US isolates were resistant to tetracycline. Resistance of Enterococcus spp. to erythromycin in our study was $21.4 \%$, compared with $19 \%$ for Finland and $60 \%$ for the United States, respectively. The $E$. coli isolates in our study expressed more resistance to streptomycin (88.5\%) than those from the
United States (2.8\%). For Staph. aureus, bacterial resistance to penicillin $\mathrm{G}$ in isolates from the United States (49.6\%) and Finland (52.1\%) was greater than in our study (16.7\%). The bacterial susceptibility results suggest that veterinarians should be more prudent and should use antimicrobials more conservatively on dairy farms, especially drugs such as sulfadimethoxine, streptomycin, oxytetracycline, amoxicillin, and cephalothin, because of their high bacterial resistance.

Amikacin, ceftifor, colistin, penicillin G, and erythromycin were the antimicrobials found to have a greater sensitivity and should be the main choice for dairy farm applications. Chloramphenicol is a useful antimicrobial for dairy farm applications, but it was banned for use in food-producing animals in Taiwan in 2002 because of concern over the occurrence of aplastic anemia. The gram-negative and gram-positive isolates showed to-

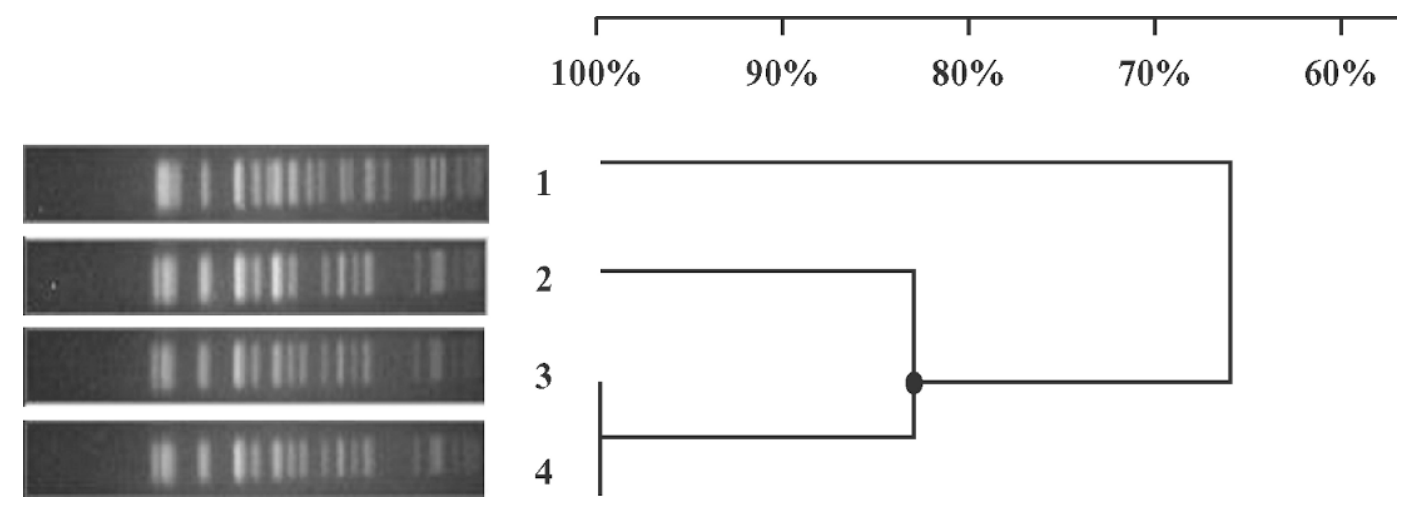

Figure 2. Dendrogram generated with BioImage software (Vilber Lourmat Co., Marne La Vallee, France) showing the pulsed-field gel

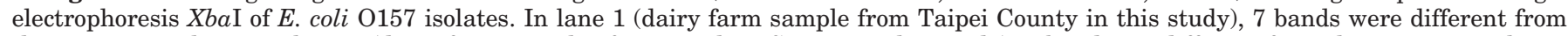
the previous isolates. In lane 2 (dairy farm samples from Hualien County in this study), 1 band was different from the previous isolates. Lanes 3 and 4 show dairy farm samples from previous isolates in Taiwan. 
tally different resistance patterns for chloramphenicol. These results indicated not only the residue of resistant gram-negative bacteria or genetic materials, but also the occurrence of environmental cross-contamination.

Observed incidence changes of resistant microbes can be used to examine the selective pressure in antimicrobial usage for animals. As shown on our questionnaire, sulfadimethoxine, oxytetracycline, streptomycin, penicillin $\mathrm{G}$, and a combination of streptomycin and penicillin $\mathrm{G}$ are the antimicrobials most commonly selected for use on dairy farms. These antimicrobial residues also were found in raw milk in our screening results. In this study, resistance to sulfadimethoxine, streptomycin, and oxytetracycline was observed in all bacteria of different genera.

In our study, gram-negative isolates from bovine and environmental samples had greater resistance to streptomycin than those from human sources. This resistance pattern showed that the bacteria found in dairy cows and their environment (dust, water, or feed) were more closely related to each other than to the bacteria found in humans. Therefore, our results support the use of antimicrobials in veterinary medicine as an important driving force in the selection for antimicrobial resistance (Schroeder et al., 2002). Alternatively, crosscontamination of samples between cow and environmental sources also was considered. We propose that if antimicrobial-resistant zoonotic bacteria are present in farm animals, the environment-borne antimicrobials might also affect resistance patterns.

The movement of resistance determinants throughout the ecosystem is complex. In this study, the authors investigated bacterial susceptibility to antimicrobials in 3 sampling venues (dairy cows, dairy workers, and dairy farm environments). Generally, bacteria from dairy workers showed a resistance pattern very close to those isolated from bovine and environmental sources. This trend was also true for different locations in Taiwan. Thus, we proposed that a rural area having less separation from the natural environment and less industrial pollution would yield a cleaner environment that would allow reduced use of antimicrobials because of fewer environmental stresses and infectious microorganisms. The percentages of resistance of 3 gram-positive bacteria-Staphylococcus spp. to doxycycline, enrofloxacin, erythromycin, and oxytetracycline; Enterococcus spp. to cephalothin, oxacillin, and sulfadimethoxine; and Streptococcus spp. to cephalothin, enrofloxacin, oxacillin, penicillin $\mathrm{G}$, and sulfadimethoxine-were greater in eastern Taiwan than in northern Taiwan. For the gram-negative bacteria, only amoxicillin had greater resistance in eastern Taiwan. Put simply, farms in eastern Taiwan, the least polluted region of Taiwan, were found to have more bacterial resistance than those in northern Taiwan. This regional difference in bacterial resistance may indicate differences in the use of antimicrobial agents in each area. These results do not support the concept that the cleaner environment in eastern Taiwan offers a better environment for raising dairy cows. Apart from pollution, bacterial susceptibility to different antimicrobials in local precincts can be one of the indices for evaluating the local strategies for therapeutics or feed additives to predict existing agents or disease patterns.

Animal-carried resistance agents of food animal origin are a cause of increased human disease risk (Witte, 1998; Cruchaga et al., 2001). Resistant strains can be significant carriers for resistant gene transmission, regardless of whether the bacterium is a pathogenic agent (i.e., resistant genes in $E$. coli can be transmitted to gram-negative and gram-positive bacteria; Courvalin, 1994). In our study, sanitary indicator bacteria (Enterococcus spp. and $E$. coli) were isolated most frequently from the bovine rectum and udder surfaces. The number of $E$. coli isolates was about 4 times greater from rectal samples than from udder surface samples, but the number of Enterococcus spp. isolates was similar (Table 1). Both bacteria had similar numbers of isolates from ground surfaces and effluent water. Among the antimicrobials tested, only streptomycin for $E$. coli showed much greater resistance to bovine rectum isolates $(86 \%)$ than to udder surface isolates $(36.7 \%)$. This result may imply that isolates have different resistances due to different environments or antiseptic effects, or because of cross-contamination, but it cannot directly explain the differences in streptomycin resistance and requires further study. Thirty-nine strains (39/226) of multiresistant $E$. coli were found in our study. Most of them were isolated from the rectum $(\mathrm{n}=$ $26)$ and udder surfaces $(n=6)$ of dairy cattle, whereas 2 were from the environment, 4 from effluent water, and only 1 from a milk sample. Possible environmental cross-contamination, the premilking antiseptic procedure, and milk hygiene need be addressed.

Staphylococcus spp. are frequently isolated from bovine mastitis, one of the most common causes for antimicrobial use in lactating dairy cows. Special attention needs to be focused on methicillin (oxacillin)-resistant Staph. aureus isolates on farms in which bacteria are closely related to human isolates and postulated to be a possible source of human infections caused by consuming contaminated food products (Lee, 2003). Eighteen ORS (18/314) were found in our study, including from worker (7/18), bovine (7/18), and environmental $(4 / 18)$ sources. Because of public health concerns and cost, oxacillin and related antimicrobials were never permitted or used in veterinary clinics in Taiwan. Furthermore, considering the total sample size ( 30 workers 
vs. 192 bovine sources), we postulated that the most reasonable source of this ORS was from dairy workers.

In our study, the resistance of bacteria from human sources to some antimicrobials (enrofloxacin, penicillin $\mathrm{G}$, and vancomycin) was generally greater than that from bovine and environmental sources. In general, an association has been suggested between the use of antimicrobial agents in animal feedstocks and an increased risk of humans contracting resistant strains (Witte, 1998; Cruchaga et al., 2001; Kidd et al., 2002). On the contrary, others (Erskine et al., 2002; Iversen et al., 2004) have shown that food-producing animals play a negligible role in the transmission of resistant strains. Our results indicate that, based on the use of and resistance to enrofloxacin and penicillin $\mathrm{G}$, the risk of transmission of antimicrobial-resistant bacteria from cow to worker seems greater than that from worker to cow. In contrast, a reversed transfer pathway could be proposed for vancomycin.

The VT-producing strain of E. coli O157:H7 (VTEC O157) is recognized as an important cause of diarrheal and zoonotic disease worldwide (Miyao et al., 1998; Dunn et al., 2004) and is a major public health concern (Kassenborg et al., 2004). In this study, 2 VTEC 0157 strains were isolated separately in July and August, in agreement with the greater prevalence of O157:H7 isolated during the warmer season by Dunn et al. (2004). The herd isolation rate in our study (12.5\%) was similar to the majority of other surveys but was greater than in a Norwegian survey $(0.35 \%$; Johnsen et al., 2001). The cow isolation rate in our survey $(1.25 \%)$ was lower than that in US surveys (6.6\%), but was greater than in a previous investigation $(0.13 \%)$ in Taiwan (Lin et al., 2001; Dunn et al., 2004). Of the 2 VTEC O157 strains, PCR analysis confirmed that the $v t 2$ genotype was similar to that in our previous study (Lin et al., 2001). However, our study marked the first isolation of E. coli O157:H7 from dairy farms in northern Taiwan. This strain had a phylogenetic similarity of $67 \%$ to our previous Taiwan isolates; thus, we considered the possibility that this isolate was unrelated to other strains and suspected a different contamination source. The strain isolated from eastern Taiwan, with $82 \%$ similarity to previous ones, was likely derived from the previous isolates by animal or feed cargo shipping that incidentally transported the pathogens. Variation between these strains indicates that further investigation by epidemiologic survey is necessary to pinpoint the different hot spots to prevent the spread of this foodborne pathogen.

Farm visits and undercooked hamburgers are the 2 major risk factors for sporadic VTEC O157 infections (Kassenborg et al., 2004). In Taiwan, Western-style fast food and agricultural tours are gaining increasing popu- larity. From a public health perspective, proper hygiene should be emphasized when people, particularly children, have direct contact with dairy cows (CDC, 2001). While realizing that multiple segments of the food industry, from farm to fork, will need to be targeted to minimize the potential for human disease, control efforts should focus on reducing the prevalence of foodborne pathogens in feedlot operations.

\section{CONCLUSIONS}

This study addressed a survey regarding antimicrobial resistance patterns in bacteria isolated from dairy cows, farm environments, and dairy farm workers. Prevalence and genetic variation also were reported. These results indicate that bacteria isolated from single sources cannot be used to represent the whole picture of farm bacterial resistance. The pattern of resistance was similar between cow and human samples. Generally, the second-line antimicrobial agents maintained their sensitivities. This information may serve as a clinical baseline for both veterinary and human medicine. The results also highlight the need for further study to prevent cross-contamination among different environments and also to formulate better regulation strategies for the safe use of antimicrobials on food-producing farms.

\section{ACKNOWLEDGMENTS}

This study was supported by grant 92AS-8.2.2-ADU1 from the Council of Agriculture, Taiwan. We thank the Animal Disease Control Centers in Taipei, Taoyuan, Hsinchu, Hualien, and Taitung Counties for their full support, and T. M. Pan and T. Y. Tsai for providing skilled techniques.

\section{REFERENCES}

Bager, F., M. Madsen, J. Christensen, and F. M. Aarestrup. 1997. Avoparcin used as a growth promoter is associated with the occurrence of vancomycin-resistant Enterococcus faecium on Danish poultry and pig farms. Prev. Vet. Med. 31:95-112.

Cannon, R. M., and R. T. Roe. 1982. Livestock Disease Surveys: A Field Manual for Veterinarians. Australian Bureau of Animal Health, Australia.

CDC (Centers for Disease Control). 2001. Outbreaks of Escherichia coli O157:H7 infections among children associated with farm visits-Pennsylvania and Washington, 2000. Morb. Mortal. Wkly. Rep. 50:293-297.

Chang, S. C., M. W. Chen, M. C. Lin, and Y. P. Hu. 2003. Antibiotic consumption in humans and animals in Taiwan. Infect. Control J. 13:334-345.

Chou, C. C., C. Y. Huang, L. J. Chiu, Y. C. Liu, Y. P. Hung, T. C. Yeh, and L. C. Lin. 2003. Antibiotic susceptibility study of isolated microbes in water-cooled broiler farm. Taiwan Vet. J. 29:393-398.

Courvalin, P. 1994. Transfer of antibiotic resistance genes between gram-positive and gram-negative bacteria. Antimicrob. Agents Chemother. 38:1447-1451. 
Craven, N., J. C. Anderson, and T. O. Jones. 1986. Antimicrobial drug susceptibility of Staphylococcus aureus isolated from bovine mastitis. Vet. Rec. 118:290-291.

Cruchaga, S., A. Echeita, A. Aladueña, J. García-Peña, N. Frias, and M. A. Usera. 2001. Antimicrobial resistance in salmonellae from humans, food and animals in Spain in 1998. J. Antimicrob. Chemother. 47:315-321.

Dunn, J. R., J. E. Keen, and R. A. Thompson. 2004. Prevalence of shiga-toxigenic Escherichia coli O157:H7 in adult dairy cattle. J. Am. Vet. Med. Assoc. 224:1151-1158.

Erskine, R. J., P. C. Bartlett, and D. G. White. 2002. Trends in antibacterial susceptibility of mastitis pathogens during a sevenyear period. J. Dairy Sci. 85:1111-1118.

Ho, M. T., L. C. McDonald, T. L. Landerdale, L. L. L. Yeh, P. C. Chen, and Y. R. Shiau. 1999. Surveillance of antibiotic resistance in Taiwan, 1998. J. Microbiol. Immunol. Infect. 32:239-249.

Iversen, A., I. Kühn, M. Rahman, A. Franklin, L. G. Burman, O. L. Barbro, E. Torell, and R. Möllby. 2004. Evidence for transmission between humans and the environment of a nosocomial strain of Enterococcus faecium. Environ. Microbiol. 6:55-59.

Johnsen, G., Y. Wasteson, E. Heir, O. I. Berget, and H. Herikstad. 2001. Escherichia coli O157:H7 in faeces from cattle, sheep and pigs in the southwest part of Norway during 1998 and 1999. Int. J. Food Microbiol. 65:193-200.

Kaneene, J. B., and R. Miller. 1992. Description and evaluation of the influence of veterinary presence on the use of antibiotics and sulfonamides in dairy herds. J. Am. Vet. Med. Assoc. 201:68-76.

Kassenborg, H. D., C. W. Hedberg, M. Hoekstra, M. C. Evans, A. E. Chin, R. Marcus, D. J. Vugia, K. Smith, S. D. Ahuja, L. Slutsker, and P. M. Griffin. 2004. Farm visits and undercooked hamburgers as major risk factors for sporadic Escherichia coli O157:H7 infection: Data from a case-control study in 5 FoodNet sites. Clin. Infect. Dis. 38:S271-S278.

Kidd, R. S., A. M. Rossignol, and M. J. Gamroth. 2002. Salmonella and other enterobacteriaceae in dairy-cow feed ingredients: Antimicrobial resistance in western Oregon. J. Environ. Health 64:9-16.
Lee, J. H. 2003. Methicillin (oxacillin)-resistant Staphylococcus aureus strains isolated from major food animals and their potential transmission to humans. Appl. Environ. Microbiol. 69:6489-6494.

Lin, Y. L., C. C. Chou, and T. M. Pan. 2001. Screening procedure from cattle feces and the prevalence of Escherichia coli O157:H7 in Taiwan dairy cattle. J. Microbiol. Immunol. Infect. 34:17-24.

Martel, J. L., F. Tardy, A. Brisabois, R. Lailler, M. Coudert, and E. Chaslus-Dancla. 2000. The French antibiotic resistance monitoring programs. Int. J. Antimicrob. Agents 14:275-283.

Miyao, Y., T. Kataoka, T. Nomoto, A. Kai, T. Itoh, and K. Itoh. 1998. Prevalence of verotoxin-producing Escherichia coli 0157 harbored in the intestine of cattle in Japan. Vet. Microbiol. 61:137-143.

NCCLS (National Committee for Clinical Laboratory Standards). 1999. Performance Standards for Antimicrobial Susceptibility Testing. 9th Int. Suppl. NCCLS document M100-S9. NCCLS, Wayne, PA.

Pan, T. M., L. M. Chen, and Y. C. Su. 2002. Identification of Escherichia coli O157:H7 by multiplex PCR with primers specific to the hlyA, eaeA, stx 1 , st $x 2$, fli , and $r f b$ genes. J. Formosa Med. Assoc. 101:661-664.

Schroeder, C. M., C. Zhao, C. DebRoy, J. Torcolini, S. Zhao, D. G. White, D. D. Wanger, P. F. McDermott, R. D. Walker, and J. Meng. 2002. Antimicrobial resistance of Escherichia coli 0157 isolated from humans, cattle, swine, and food. Appl. Environ. Microbiol. 68:576-581.

Wallmann, J., K. Schröter, L. H. Wieler, and R. Kroker. 2003. National antibiotic resistance monitoring in veterinary pathogens from sick food-producing animals: The German programme and results from the 2001 pilot study. Int. J. Antimicrob. Agents 22:420-428.

Witte, W. 1998. Medical consequences of antibiotic use in agriculture. Science 279:996-997.

WHO (World Health Organization). 2001. WHO global strategy for containment of antimicrobial resistance. Department of Communicable Disease Surveillance and Response. WHO/CDS/CSR/ DRS/2001.2. WHO, Geneva, Switzerland. 